\title{
REINFORCEMENT OF INNER AND OUTER CIRCULAR FAILURES OF PIPES BY TEXTILE COMPOSITE LAYERS
}

\author{
Balázs Pere, János Égert and Tamás Szabó \\ Department of Applied Mechanics, Széchenyi István University, \\ Egyetem tér 1., 9026 Győr, Hungary \\ perebal@sze.hu, egert@sze.hu, sztamas@sze.hu
}

[Received: September 15, 2008]

\begin{abstract}
The first part of the paper deals with the FEM computation of deformations, stresses and strain in the surrounding area of inner and outer circular artificial failures with a set of given geometrical dimensions in steel pipelines. For the investigation of this problem three groups of mechanical models are applied: multilayered elastic shell, 3D elastic solid and 3D elastic-plastic solid FEM models. The aim of this analysis is to clarify the case in which the pipeline fails. When a pipe fails and needs repair or reinforcement, this is called critical case.

In the second part of the paper the repaired pipes are investigated. For repairing of the inner and outer failures, inner or outer multilayered textile composite reinforcements are applied by winding technology. The task is to determine the width of the reinforcement and the number of layers needed for repair.

The different mechanical models (multilayered elastic shell, 3D elastic solid and 3D elastoplastic solid) are compared on the basis of numerical results. The critical cases are determined and the questions of repair are answered also numerically.
\end{abstract}

Keywords: Steel pipeline, artificial circular damage, textile composite reinforcement, FEM analysis, elastic shell and 3D elastic-plastic modelling

\section{INTRODUCTION}

Oil and gas pipelines often have inner and outer circular failures. The inner failures usually originate from welding on location, and the outer failures result from any other violent outer effect, for instance due to agricultural equipment working above the pipeline.

The first task is to predict the risk caused by these circular failures. In the first step one needs to clarify the deformations, stresses and strains around the damaged part of the pipe. On the basis of such analysis one can find critical cases in which repairs are needed.

The second task is to fix or to repair the damaged pipe. In this paper an inner or outer multilayered textile composite reinforcement are applied at the location of the failures. The multilayered textile composite reinforcement is made by winding technology. During design of this composite reinforcement the width and the number 
of layers of the winding should be determined. The failures are considered to be fixed when stresses are below the critical values both in the steel pipe and in the composite reinforcement.

The numerical aspects of both tasks are discussed in this paper. In the first step two kinds of circular damaged pipe-parts using the finite element method and the I-DEAS program code are investigated. The failures may have a high number of varieties therefore two typical artificial failure geometries are chosen. On the basis of the numerical analysis the critical cases have been determined in which repairs are needed. In the second step an inner and/or outer composite reinforcement with different widths and numbers of layers are applied for the critical cases. When analyzing critical cases the proper width and number of layers of reinforcement can be found.

\section{Geometry of typical ARTificial failures AND REINFOrCEMEnts}

Figure 1 shows the global geometry i.e. the location of the investigated inner and outer circular failures.

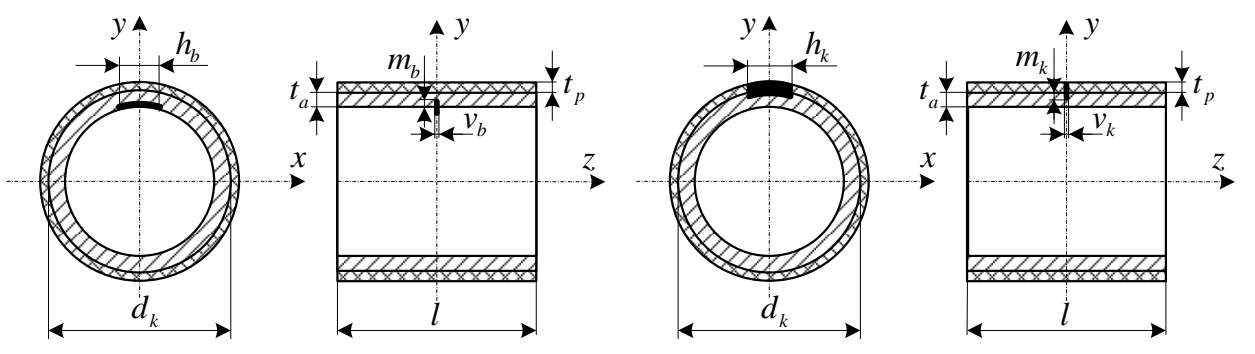

Figure 1. Global geometry of the inner and outer circular failures

The steel pipe's outer diameter is $d_{k}=323,9 \mathrm{~mm}$, its wall thickness $t_{a}=7,1$ $\mathrm{mm}$ and the length of the investigated pipe part is $l=2000 \mathrm{~mm}$. The steel pipe is coated with a $t_{p}=3,12 \mathrm{~mm}$ thick polyethylene insulation layer against corrosion. The longitudinal dimension of circular failures are $h_{b}=h_{k}=150 \mathrm{~mm}$ for both inner and outer cases, the width is $v_{b}=1,5 \mathrm{~mm}$ for the inner case and $v_{k}=2 \mathrm{~mm}$ for the outer case. There are three depth versions $m_{b}=m_{k}=2 ; 4 ; 6 \mathrm{~mm}$ investigated.

Figure 2 shows the the local geometry of analyzed inner and outer circular failures. The geometry of artificial failures (Figure 2) are assumed to be reproduced easily for the planned experiments.
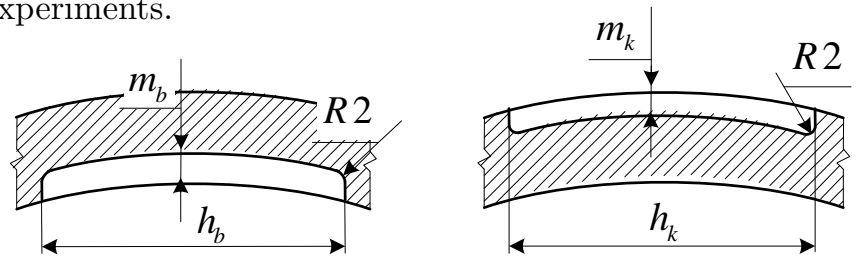

Figure 2. Local geometry of the inner and outer circular failures 
An inner and outer circular failures of pipes can be reinforced theoretically from the outside or the inside as well. Figure 3 shows the reinforcement possibilities for an inner failure. At the location of the failure the anti-corrosion layer is removed and the reinforcement is winded directly to the steel surface.

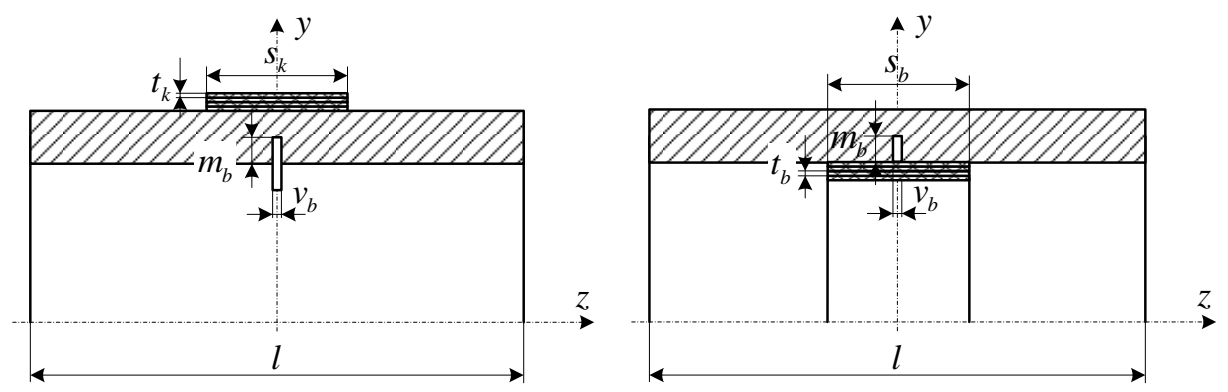

Figure 3. Reinforcement versions for the inner circular damage

The layer thickness of reinforcement in each case is the same $t_{k}=t_{b}=0,3 \mathrm{~mm}$, and three different widths of the winding bands are investigated $s_{k}=s_{b}=50 ; 100 ; 200$ mm.

\section{Mechanical modelling of the MATERIALS AND WORKING CONDitions}

The pipe is made of steel, the protecting layer against corrosion is polyethylene and the material of the reinforcement is carbon fiber textile reinforced plastics (CFRP). In mechanical point of view the steel and the polyethylene are modelled as linear elastic materials given by two material constants and the limit of elasticity. These material parameters in Table 1 are measured by the Department of Mechanical Technology of Miskolc University [7].

Table 1. Material constants and ultimate stress values

\begin{tabular}{|c|c|c|c|c|}
\hline Material & $\mathbf{E}[\mathrm{MPa}]$ & $\nu[-]$ & $\mathbf{R}_{\mathbf{t o}, \mathbf{5}}[\mathrm{MPa}]$ & $\mathbf{R}_{\mathbf{m}}[\mathrm{MPa}]$ \\
\hline \hline Steel & 205000 & 0,3 & 499 & 603 \\
\hline Polyethylene & 527 & 0,31 & - & 12,8 \\
\hline
\end{tabular}

In Table $1 E$ is the modulus of elasticity, $\nu$ is the Poisson's ratio, $\mathbf{R}_{\mathbf{t o , 5}, \mathbf{5}}$ is the yield limit and $\mathbf{R}_{\mathbf{m}}$ is the breaking strength of material.

In linear elastic, isotropic, plane stress problems the following Hooke's law provides the constitutive equations:

$$
\left[\begin{array}{c}
\varepsilon_{1} \\
\varepsilon_{2} \\
\gamma_{12}
\end{array}\right]=\left[\begin{array}{ccc}
\frac{1}{E} & -\frac{\nu}{E} & 0 \\
-\frac{\nu}{E} & \frac{1}{E} & 0 \\
0 & 0 & \frac{2(1+\nu)}{E}
\end{array}\right]\left[\begin{array}{c}
\sigma_{1} \\
\sigma_{2} \\
\tau_{12}
\end{array}\right],
$$


1 and 2 are directions perpendicular to each other in the tangent plane of the middle surface of pipe. $\varepsilon_{1}, \varepsilon_{2}$ and $\sigma_{1}, \sigma_{2}$ are tensions and normal stresses in directions 1,2 respectively. $\gamma_{12}$ and $\tau_{12}$ are the in-plane shear strain and the shear stress.

The elasto-plastic computations are carried out by using the stress-strain diagram in Figure 4 given by the Department of Mechanical Technology of Miskolc University $[7]$.

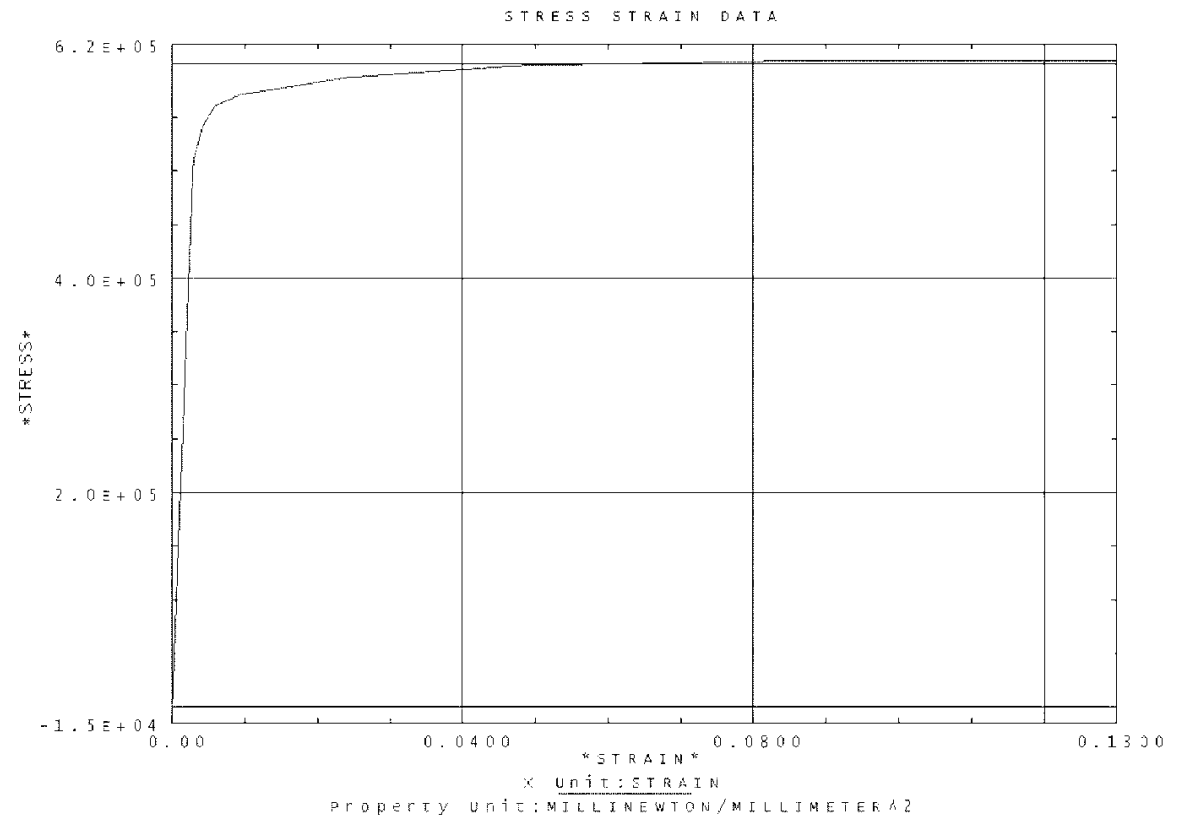

Figure 4. Stress-strain diagram of the steel pipe

For isotropic materials the well known von Mises failure criterium is applied:

$$
\begin{gathered}
\frac{1}{2}\left(\frac{1}{R_{t 0,5}}\right)^{2}\left[\left(\sigma_{I}-\sigma_{I I}\right)^{2}+\left(\sigma_{I I}-\sigma_{I I I}\right)^{2}+\left(\sigma_{I}-\sigma_{I I I}\right)^{2}\right] \leq 1, \quad \text { or } \\
\sigma_{\text {red } \max } \leq R_{t 0,5},
\end{gathered}
$$

where $\sigma_{I}, \sigma_{I I}, \sigma_{I I I}$ are the principal stresses.

According to references [1], [2], the carbon fiber textile reinforced composite can be modelled from macroscopic point of view by an orthotropic constitutive law:

$$
\left[\begin{array}{c}
\varepsilon_{1} \\
\varepsilon_{2} \\
\gamma_{12}
\end{array}\right]=\left[\begin{array}{ccc}
1 / E_{1} & -\nu_{12} / E_{2} & 0 \\
-\nu_{21} / E_{1} & 1 / E_{2} & 0 \\
0 & 0 & 1 / G_{12}
\end{array}\right]\left[\begin{array}{c}
\sigma_{1} \\
\sigma_{2} \\
\tau_{12}
\end{array}\right],
$$


In the above equations the indices 1,2 stand for the principal material direction of CFRP. In the constitutive law $E_{1}, E_{2}$ are orthotropic moduli of elasticity, $\nu_{12}, \nu_{21}$ are Poisson's ratios and $G_{12}$ is the independent in-plane shear modulus. The Poisson's ratios are not independent from each other and due to energy reasons [2] the following relation exists :

$$
\frac{\nu_{12}}{E_{2}}=\frac{\nu_{21}}{E_{1}} .
$$

Macroscopic modelling means that equations are not appropriate to determine stresses and strains in the carbon fibers or in the matrix material, but do well for a larger area with a lot of fibers. Therefore, the above stresses and strains are the average features of an area with a lot of fibers.

For the orthotropic material the Tsai-Wu's failure criterium is applied:

$$
\begin{aligned}
& \frac{\sigma_{1}^{2}}{\sigma_{H 1} \sigma_{D 1}}+\frac{\sigma_{2}^{2}}{\sigma_{H 2} \sigma_{D 2}}-\frac{\sigma_{1} \sigma_{2}}{\sqrt{\sigma_{H 1} \sigma_{D 1} \sigma_{H 2} \sigma_{D 2}}}+\frac{\tau_{12}^{2}}{\tau_{S 12}^{2}}+ \\
& \quad+\left(\frac{1}{\sigma_{H 1}}-\frac{1}{\sigma_{D 1}}\right) \sigma_{1}+\left(\frac{1}{\sigma_{H 2}}-\frac{1}{\sigma_{D 2}}\right) \sigma_{2} \leq 1,
\end{aligned}
$$

or

$$
K_{t w} \leq 1
$$

where $\sigma_{H 1}, \sigma_{H 2}$ are tensile, $\sigma_{D 1}, \sigma_{D 2}$ are compressive and $\tau_{S 12}$ is shear strengths.

Table 2 contains the measured material constants and ultimate stress values of the

\begin{tabular}{|c|c|c|c|c|c|c|c|}
\hline Thickne & {$[\mathrm{mm}]$} & & {$[\overline{\mathrm{Pa}}]$} & $\mathbf{E}_{2}$ & & $\nu[-]$ & $\mathbf{G}_{12}[\mathrm{MPa}]$ \\
\hline \multicolumn{2}{|l|}{0,3} & \multicolumn{2}{|c|}{$\overline{476600}$} & \multicolumn{2}{|c|}{45000} & 0,036 & 2000 \\
\hline$\sigma_{\mathbf{H 1}}[\mathrm{MPa}]$ & \multicolumn{2}{|c|}{$\sigma_{\mathbf{H} 2}[\mathrm{MPa}]$} & \multicolumn{2}{|c|}{$\sigma_{\mathrm{D} \mathbf{1}}[\mathrm{MPa}]$} & \multicolumn{2}{|c|}{$\sigma_{\mathrm{D} \mathbf{2}}[\mathrm{MPa}]$} & $\sigma_{\mathrm{S} 12}[\mathrm{MPa}]$ \\
\hline 436 & \multicolumn{2}{|c|}{430} & \multicolumn{2}{|c|}{310} & \multicolumn{2}{|c|}{340} & 76 \\
\hline
\end{tabular}
applied CFRP measured by the Department of Polymer Engineering of the Budapest University of Technology [8].

Table 2. Material constants and ultimate stress values of CFRP layers

The deformations, stresses and strains in the damaged pipe and in the reinforced pipe are determined for two loading cases, i.e. for a normal working condition and for an experimental loading, where it is possible to measure by gauges.

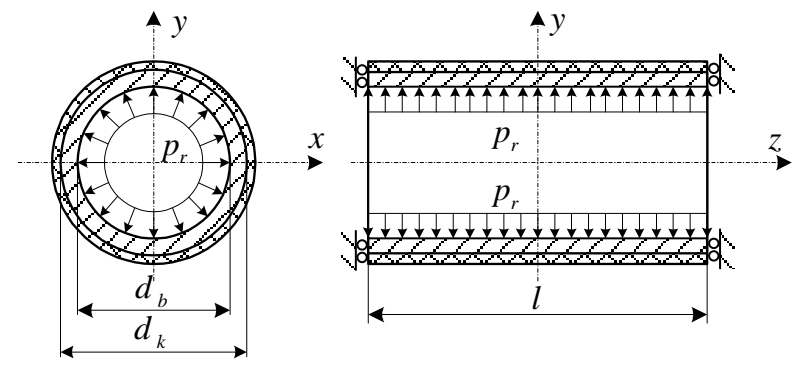

Figure 5. Mechanical model for normal working condition 
In normal working conditions the pipeline is embedded in the earth which does not allow the longitudinal displacements of the investigated pipe parts. This is the reason why the mechanical model is clamped at both ends of the pipe part in the normal working loading case. There is a $p_{r}=63$ bar inner pressure in both loading cases in the pipe.

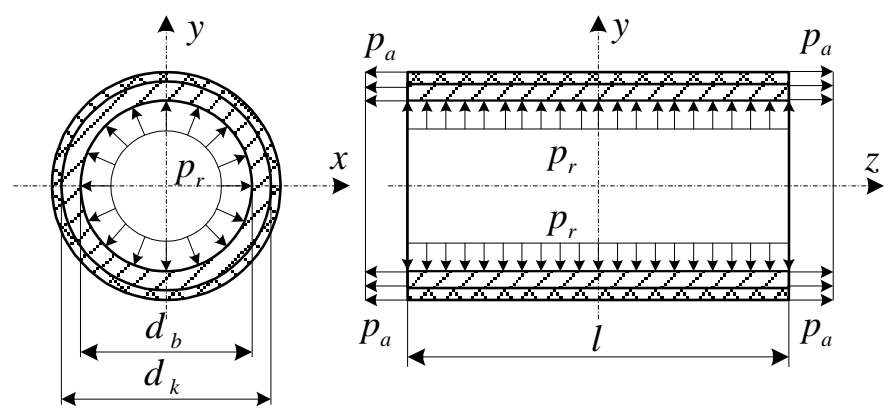

Figure 6. Mechanical model for experimental checking

In the experiments the investigated pipe part is closed at both ends. The inner pressure provides an $p_{a}=d_{b}^{2} p_{r} /\left(d_{k}^{2}-d_{b}^{2}\right)$ additional axial loading because of the closed ends. Therfore the experimental loading case consists of the inner pressure and the axial loading.

\section{Finite Element APproaches AND Meshes}

For computation of deformations, stresses and strains around the circular failures the following three models are applied: multilayered elastic shell, 3D elastic solid and 3D elasto-plastic solid elements. However computations of repaired pipes are carried out only by multilayered elastic shell elements.

By using layered shell elements it is possible to model failures by proper choice of layer thicknesses. Figure 7 shows two cases for the proper thickness choice. The left one is at a common location of the pipe and the right one is at an inner failure with $4 \mathrm{~mm}$ depth. In both cases in Figure 7 the upper layer represents the insulation and two inner layers for modelling the inner failure are shown in the right picture. Naturally, for the failure area zero values should be given for material constants.

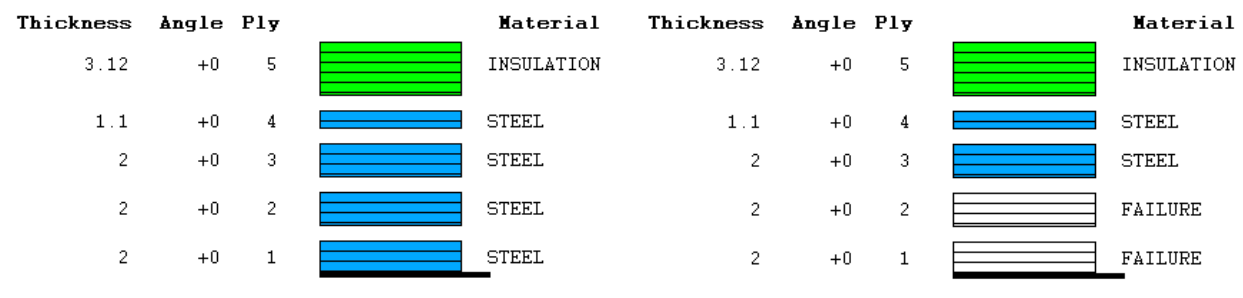

Figure 7. Modelling of failure thickness by multilayered shell elements 
Figure 8 shows two cases for the proper thickness choice of layers at reinforcement. The left and right pictures represent the thicknesses of layers in undamaged and damaged locations, respectively.
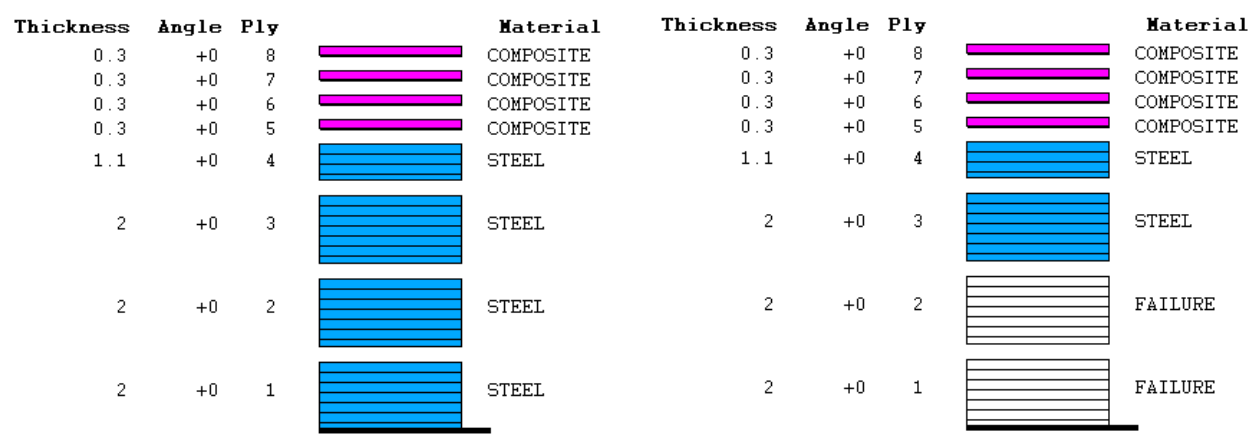

Figure 8. Modelling of reinforcement and failure thickness by shell elements

Using multilayered shell elements it is only possible to apply a sharp corner approach for failures, so the $\mathrm{R} 2 \mathrm{~mm}$ rounding in Figure 2 is not taken into consideration at shell modelling.

The 3D modelling allows a very accurate approach of real geometry of artificial inner and outer failures, even an $\mathrm{R} 2 \mathrm{~mm}$ rounding.

Table 3. Characteristic data for FEM meshes

\begin{tabular}{|c|c|c|}
\hline & Shell model & 3D solid model \\
\hline \hline Number of elements & 5000 & 17500 \\
\hline Number of nodes & 15000 & 36000 \\
\hline
\end{tabular}

Table 3 includes the characteristic data of applied meshes. The nodes of shell elements have six degrees of freedom and the nodes of $3 \mathrm{D}$ solid elements three, so one has to solve in both tasks a linear algebraic equation system with about 90-108 thousand unknowns. The computations for both shell and 3D solid modelling are carried out also with much denser mesh in order to prove that the applied mesh provides accurate results.

When creating finite element meshes the double symmetry is taken into account. Naturally, the mesh is much denser around the failures than at the other areas of the model in interest of accuracy of computations.

Figure 9 shows a characteristic mesh for a shell model and a mesh part for a 3D solid model. The $l_{m}=l / 2=1000 \mathrm{~mm}$ length of mesh is chosen so that the influence of boundary conditions at the end of the pipe part and the influence of the circular failure do not disturb each other. 

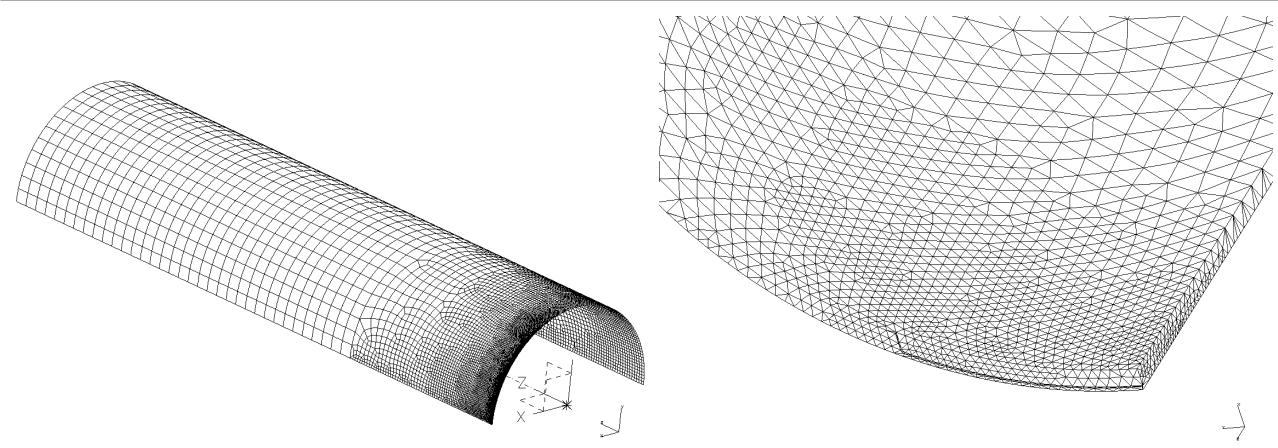

Figure 9. Shell mesh and 3D solid mesh part for circular failure
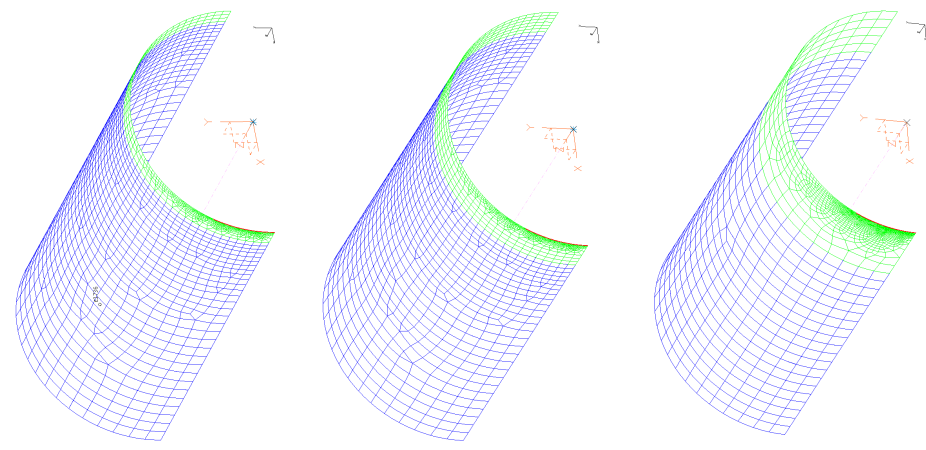

Figure 10. Shell meshes for different reinforcements

On the basis of computational experience it is enough to apply shorter models with $l_{r}=l_{m} / 2=500 \mathrm{~mm}$ length for the computation of reinforced pipe parts. In these meshes one has to take into consideration the width of the reinforcing composite band at meshing (Figure 10.).

\section{Computational Results}

5.1. Influence of the insulation layer. The analysis of the influence of the outer polyethylene insulation is carried out only for inner circular failure. Numerical results prove that the insulation layer has no importance from the mechanical point of view, since the stiffness of the insulation layer is negligible compared to the steel's stiffness. Therefore the insulation layer is neglected in the investigations.

5.2. Results for the damaged steel pipes. The character of deformations and stress/strain distributions is similar for both loading cases. However the critical values of deformations, stresses and strains are a little higher for the experimental checking than for the normal loading conditions. This is the consequence of the additional axial loading originated from the inner pressure. This axial loading seems to be a little higher than the axial loading originated from the clamped ends of the pipe 
model at normal working conditions. Therefore, only the results of this hazardous experimental loading case are presented in this paper.

Numerical results show that the deformation of pipes with inner failure depends significantly on the depth of failure. Figure 11 demonstrates these differences on the radial displacement distribution of the middle surface. It is very interesting that the maximum deformation occurs not directly at the failure but beside that.
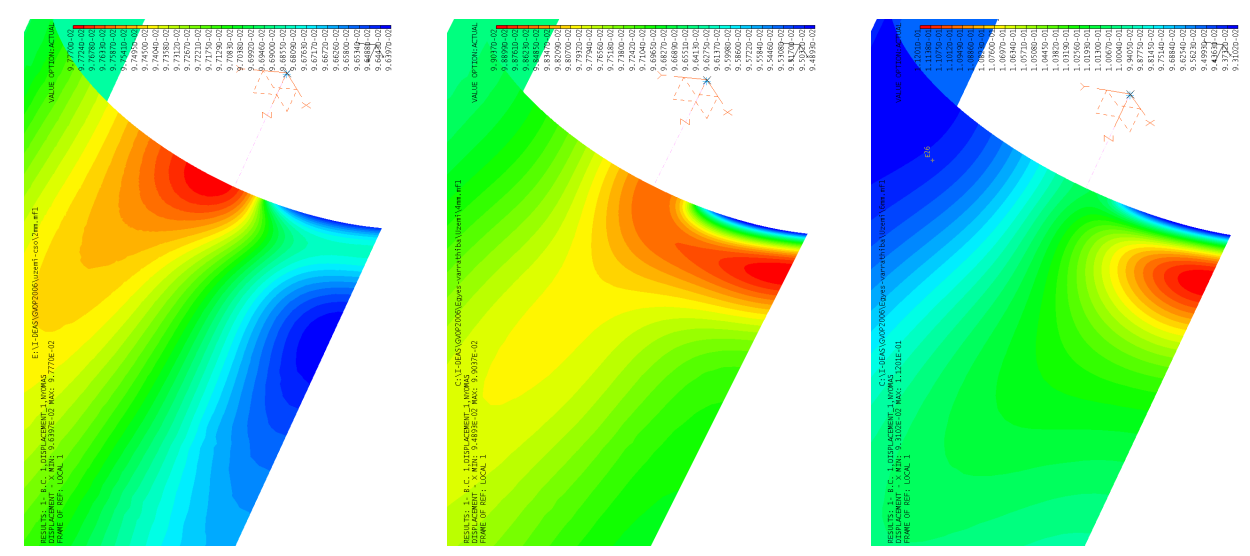

Figure 11. Radial displacements at inner failure with 2, 4 and $6 \mathrm{~mm}$ depth

Figure 12 shows the radial displacements in case of outer failure for the three investigated failure depths. In this case the character of deformation does not depend on the depth of outer failure. Naturally, the magnitudes of deformation are different.
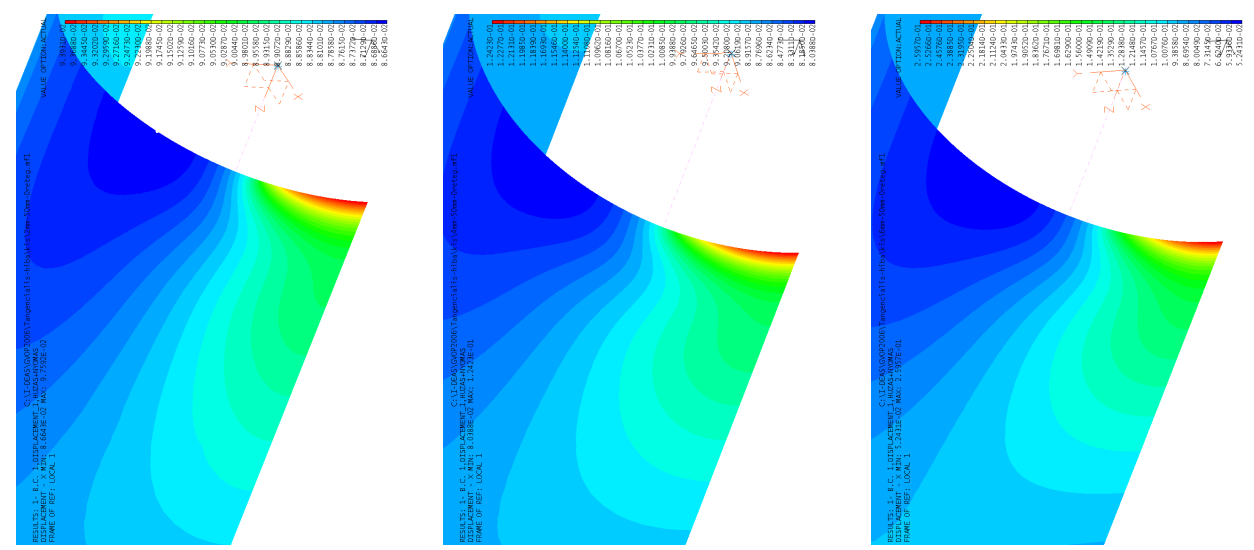

Figure 12. Radial displacements at outer failure with 2, 4 and $6 \mathrm{~mm}$ depth

The different character of deformations for inner and outer failure will play a very important role at the repair. 
Table 4 summarizes the critical strain and von Mises reduced stress values for the hazardous experimental loading case at inner failure. Compering the $\varepsilon_{z \text { max }}$ axial and $\varepsilon_{\varphi \max }$ circular strains it is seen that they are in the same order of magnitude at lower depths. However the $\varepsilon_{z \max }$ axial strains become dominant at increasing failure depth. Therefore one can state that the influence of axial loading is dominant for strains around the circular failure at higher depths.

Table 4. Critical values - inner failures - experimental loading case

\begin{tabular}{|c|c|c|c|c|}
\hline $\begin{array}{c}\text { Depth } \\
{[\mathrm{mm}]}\end{array}$ & $\begin{array}{c}\text { Quantity } \\
{[\text { Dimension }]}\end{array}$ & Shell model & $\begin{array}{c}\text { 3D elastic } \\
\text { model }\end{array}$ & $\begin{array}{c}\text { 3D elasto- } \\
\text { plastic model }\end{array}$ \\
\hline \hline \multirow{3}{*}{2} & $\varepsilon_{\varphi \max }[1]$ & $1,2603 \cdot 10^{-3}$ & $9,3827 \cdot 10^{-4}$ & $9,3827 \cdot 10^{-4}$ \\
\cline { 2 - 5 } & $\varepsilon_{z \max }[1]$ & $1,0610 \cdot 10^{-3}$ & $1,2283 \cdot 10^{-3}$ & $1,2283 \cdot 10^{-3}$ \\
\cline { 2 - 5 } & $\sigma_{\text {red } \max }[\mathrm{MPa}]$ & 222,37 & 243,03 & 243,03 \\
\hline \multirow{4}{*}{4} & $\varepsilon_{\varphi \max }[1]$ & $2,4310 \cdot 10^{-3}$ & $8,7135 \cdot 10^{-4}$ & $8,7235 \cdot 10^{-4}$ \\
\cline { 2 - 5 } & $\varepsilon_{z \max }[1]$ & $7,2919 \cdot 10^{-3}$ & $2,5820 \cdot 10^{-3}$ & $2,5820 \cdot 10^{-3}$ \\
\cline { 2 - 5 } & $\sigma_{\text {red max }}[\mathrm{MPa}]$ & 502,38 & 455,11 & 455,11 \\
\hline \multirow{4}{*}{6} & $\varepsilon_{\varphi \max }[1]$ & $2,8736 \cdot 10^{-3}$ & $9,3700 \cdot 10^{-4}$ & $9,4239 \cdot 10^{-4}$ \\
\cline { 2 - 5 } & $\varepsilon_{z \max }[1]$ & $3,5439 \cdot 10^{-2}$ & $6,7759 \cdot 10^{-3}$ & $7,4800 \cdot 10^{-3}$ \\
\cline { 2 - 5 } & $\sigma_{\text {red max }}[\mathrm{MPa}]$ & $\mathbf{8 9 8 , 8 5}$ & $\mathbf{1 1 9 1 , 4}$ & $\mathbf{6 0 3 , 0}$ \\
\hline
\end{tabular}

The maximum reduced stresses computed by different models are close to each other below the yield stress, in cases of 2 and $4 \mathrm{~mm}$ deep inner failures. At $4 \mathrm{~mm}$ failure depth the maximum reduced stresses reach or are close to the yield stress value. For $6 \mathrm{~mm}$ failure depth every model, including the shell model, indicates the fracture of the pipe. Therefore the damaged pipe needs repair only at $6 \mathrm{~mm}$ failure depth.

Table 5. Critical values - outer failures - experimental loading case

\begin{tabular}{|c|c|c|c|c|}
\hline $\begin{array}{c}\text { Depth } \\
{[\mathrm{mm}]}\end{array}$ & $\begin{array}{c}\text { Quantity } \\
{[\text { Dimension }]}\end{array}$ & Shell model & $\begin{array}{c}\text { 3D elastic } \\
\text { model }\end{array}$ & $\begin{array}{c}\text { 3D elasto- } \\
\text { plastic model }\end{array}$ \\
\hline \hline \multirow{3}{*}{2} & $\varepsilon_{\varphi \max }[1]$ & $8,9118 \cdot 10^{-4}$ & $9,8610 \cdot 10^{-4}$ & $9,8610 \cdot 10^{-4}$ \\
\cline { 2 - 5 } & $\varepsilon_{z \max }[1]$ & $7,2939 \cdot 10^{-4}$ & $1,1496 \cdot 10^{-3}$ & $1,1496 \cdot 10^{-3}$ \\
\cline { 2 - 5 } & $\sigma_{\text {red } \max }[\mathrm{MPa}]$ & 196,39 & 233,38 & 233,38 \\
\hline \multirow{4}{*}{4} & $\varepsilon_{\varphi \max }[1]$ & $1,1614 \cdot 10^{-3}$ & $1,1841 \cdot 10^{-3}$ & $1,1841 \cdot 10^{-3}$ \\
\cline { 2 - 5 } & $\varepsilon_{z \max }[1]$ & $2,5196 \cdot 10^{-3}$ & $2,7328 \cdot 10^{-3}$ & $2,7328 \cdot 10^{-3}$ \\
\cline { 2 - 5 } & $\sigma_{r e d \max }[\mathrm{MPa}]$ & 531,40 & 490,62 & 490,62 \\
\hline \multirow{4}{*}{6} & $\varepsilon_{\varphi \max }[1]$ & $1,4874 \cdot 10^{-3}$ & $1,6668 \cdot 10^{-3}$ & $1,6706 \cdot 10^{-3}$ \\
\cline { 2 - 5 } & $\varepsilon_{z \max }[1]$ & $4,8891 \cdot 10^{-3}$ & $5,5436 \cdot 10^{-3}$ & $7,1033 \cdot 10^{-3}$ \\
\cline { 2 - 5 } & $\sigma_{r e d \max }[\mathrm{MPa}]$ & $\mathbf{1 0 0 9 , 7}$ & $\mathbf{9 7 3 , 5 8}$ & $\mathbf{6 0 3 , 0}$ \\
\hline
\end{tabular}


Table 5 summarizes the characteristic critical strain and von Mises reduced stress values for the more hazardous experimental loading case at outer failure. These results show very similar behavior from the point of view of strains and stresses for the outer damaged pipe than for the inner failure. Also the outer damaged pipe needs repair only at $6 \mathrm{~mm}$ failure depth.

It is curious that though the deformations are different similar strain and stress values have been obtained for the inner and outer failures.

All the three applied models indicate the fracture of the pipe for the same failure depth. From here on the simplest multilayered shell model is used in the investigation of repaired cases because it needs less numerical efforts than the others.

5.3. Results for the pipes repaired. As it is determined in 5.2 the axial loading becomes dominant at both increasing inner and outer circular failure depths. This dominant loading results very different deformations at inner (Figure 13.) and outer (Figure 14.) failure. The highest radial deformations occur shifted in axial direction nearby the inner failure and exactly in the middle of the outer failure.
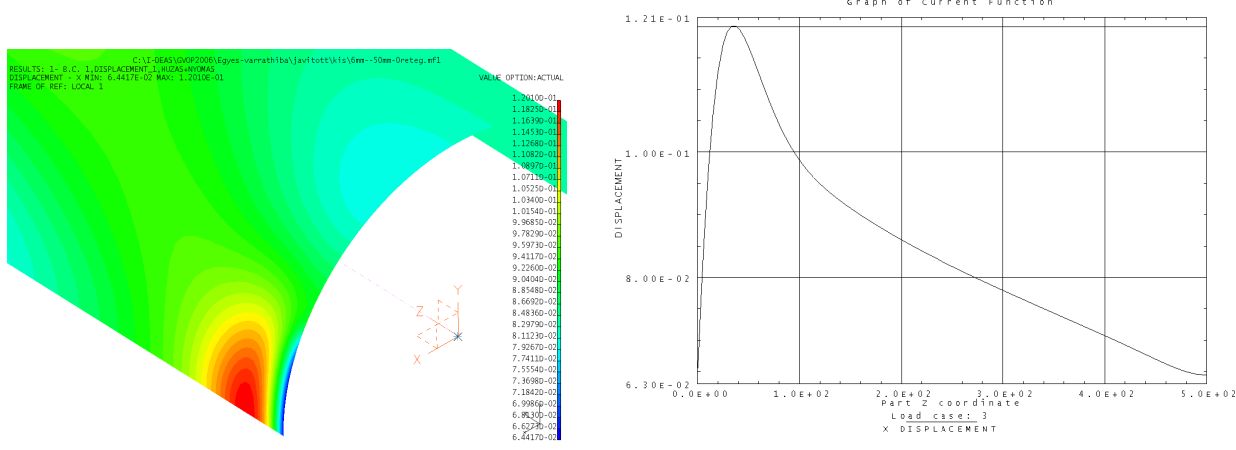

Figure 13. Radial displacements at inner failure with $6 \mathrm{~mm}$ depth
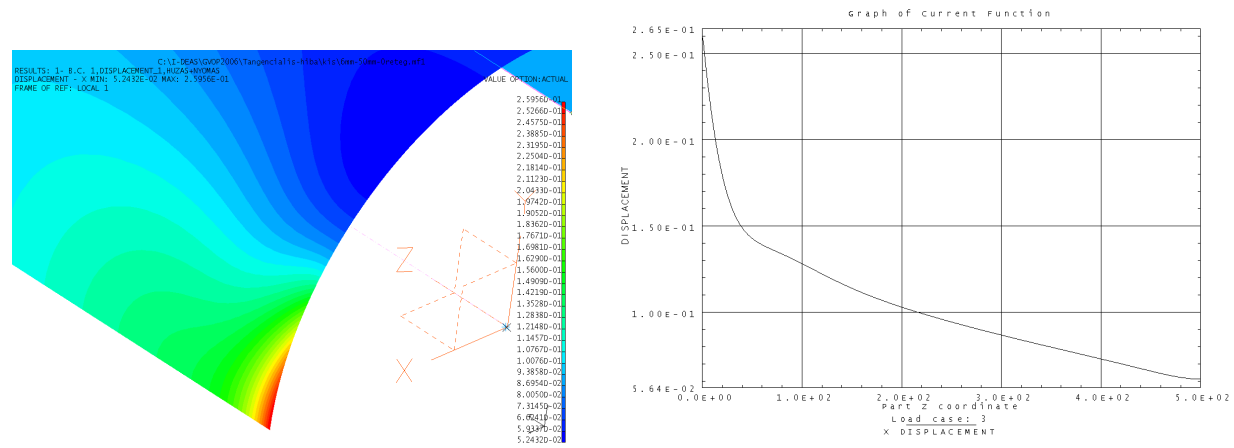

Figure 14. Radial displacements at outer failure with $6 \mathrm{~mm}$ depth 
The phenomenon can be explained by Figure 15. If there is no failure in the pipe wall the stress resultant over the thickness is only the $N_{a}$ force. In the undamaged case there is no bending effect in the pipe wall.

However in case of inner failure the stress resultants provide a $N_{a}$ force and an additional $M_{t i}$ bending moment. This bending moment opens the inner failure and results maximum radial deformations shifted nearby the failure.

In case of outer failure the stress resultants provide a $N_{a}$ force and an additional $M_{t o}$ bending moment. This bending moment also opens the outer failure and results maximum radial deformations in the middle of the failure.
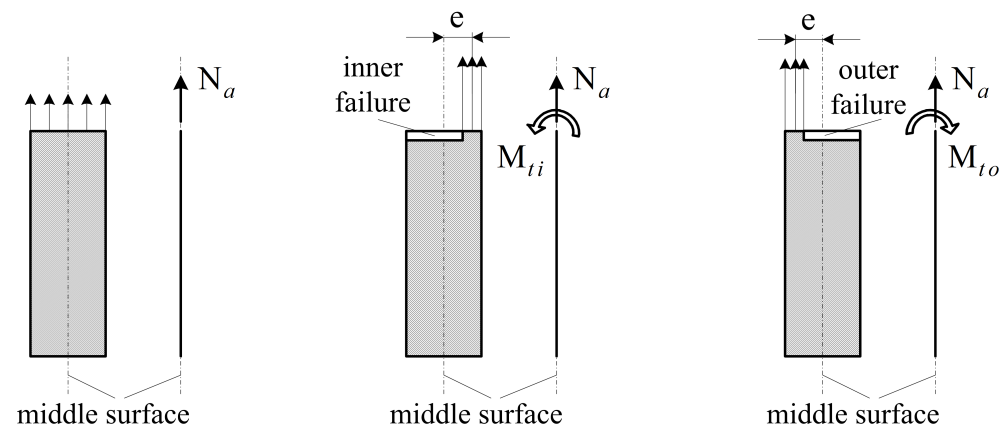

Figure 15. Force and moment resultants at inner and outer failure

Both inner and outer failures can be fixed from the outside or from the inside. Figure 16. shows the repair versions for an inner failure.

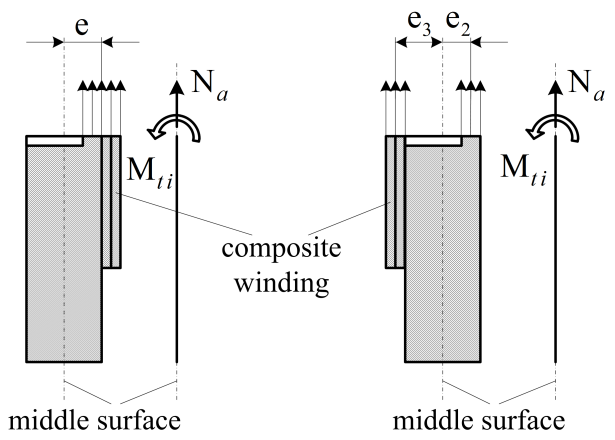

Figure 16. Reparation versions at inner failure

The pipe can be considered as fixed if the $\sigma_{\text {red max }}$ reduced stresses in the steel wall do not reach the yield stress value (3.3) and the $K_{t w}$ Tsai-Wu failure coefficient in the reinforcement do not reach the value $1(3.7)$. 
Computations are carried out for repaired inner failure by 50, 100 and $200 \mathrm{~mm}$ bandwidth of CFRP layers. The numerical results proved that the bandwidth in this range practically does not influence the behavior of repaired case.

Table 6 summarizes the numerical results for a $6 \mathrm{~mm}$ deep inner failure with 50 $\mathrm{mm}$ bandwidth reinforcement, in the left two columns for outer reinforcement and in the right two columns for inner reinforcement.

Table 6. Reduced stresses and failure coefficients for inner failure with $6 \mathrm{~mm}$ depth

\begin{tabular}{|c|c|c|c|c|}
\hline $\begin{array}{c}\text { Number of layers/ } \\
\text { thickness }[\mathbf{m m}]\end{array}$ & $\begin{array}{c}\sigma_{\text {red max }}^{\text {outer }} \\
{[\mathrm{MPa}]}\end{array}$ & $\begin{array}{c}\mathbf{K}_{\text {tw }}^{\text {outer }} \\
{[-]}\end{array}$ & $\begin{array}{c}\sigma_{\text {red max }}^{\text {inner }} \\
{[\mathrm{MPa}]}\end{array}$ & $\begin{array}{c}\mathbf{K}_{\text {tw }}^{\text {iner }} \\
{[-]}\end{array}$ \\
\hline \hline $0 / 0$ & 908 & - & 908 & - \\
\hline $4 / 1,2$ & 1046,0 & 0,6137 & 600,2 & 0,0641 \\
\hline $8 / 2,4$ & 984,4 & 0,7704 & 499,1 & $-0,0187$ \\
\hline $12 / 3,6$ & 804,6 & 0,4633 & - & - \\
\hline $16 / 4,8$ & 674,1 & 0,2729 & - & - \\
\hline $20 / 6,0$ & 586,0 & 0,1909 & - & - \\
\hline $24 / 7,2$ & 523,0 & 0,1188 & - & - \\
\hline $28 / 8,4$ & 475,5 & 0,0862 & - & - \\
\hline
\end{tabular}

It can be seen from Table 6 that an inner circular failure can be repaired better by inner reinforcement than by outer one. Both goals for failure criteria (3.3) and (3.87) can already be fulfilled by 8 layers of inner winding. The outer reinforcement with a low number of layers makes the situation worse and the pipe can only be fixed with a very high number of layers.

Table 7. Reduced stresses and failure coefficients for outer failure with $6 \mathrm{~mm}$ depth

\begin{tabular}{|c|c|c|c|c|}
\hline $\begin{array}{c}\text { Number of layers/ } \\
\text { thickness }[\mathrm{mm}]\end{array}$ & $\begin{array}{l}\sigma_{\text {red max }}^{\text {outer }} \\
{[\mathrm{MPa}]}\end{array}$ & $\begin{array}{c}\mathbf{K}_{\text {tw }}^{\text {outer }} \\
{[-]}\end{array}$ & $\begin{array}{c}\sigma_{\text {red max }}^{\text {inner }} \\
{[\mathrm{MPa}]}\end{array}$ & $\begin{array}{c}\mathbf{K}_{\text {tw }}^{\text {inner }} \\
{[-]}\end{array}$ \\
\hline $0 / 0$ & 1009,7 & 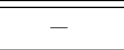 & 1009,7 & - \\
\hline $4 / 1,2$ & 550,2 & 0,0704 & 1125,5 & 0,7026 \\
\hline $8 / 2,4$ & 499,2 & 0,0111 & 1017,3 & 0,8056 \\
\hline $12 / 3,6$ & - & - & 825,1 & 0,4745 \\
\hline $16 / 4,8$ & - & - & 692,3 & 0,2791 \\
\hline $20 / 6,0$ & - & - & 602,8 & 0,1807 \\
\hline $24 / 7,2$ & - & - & 539,4 & 0,1280 \\
\hline $28 / 8,4$ & - & - & 491,9 & 0,0974 \\
\hline
\end{tabular}

This phenomenon can be explained by Figure 16. With a lower number of outer layers the $e$ eccentricity is increased by the reinforcement which makes the $M_{t i}$ local bending moment higher but a high enough number of layers can compensate this action. However the inner reinforcement creates an opposite bending moment by $e_{3}$ eccentricity which can balance the original bending moment. 
Table 7 summarizes the numerical results for a $6 \mathrm{~mm}$ deep outer failure with 50 $\mathrm{mm}$ bandwidth reinforcement, in the left two columns for outer reinforcement and in the right two columns for inner reinforcement.

Table 7. Reduced stresses and failure coefficients for outer failure with $6 \mathrm{~mm}$ depth

\begin{tabular}{|c|c|c|c|c|}
\hline $\begin{array}{c}\text { Number of layers/ } \\
\text { thickness }[\mathrm{mm}]\end{array}$ & $\begin{array}{c}\sigma_{\text {red max }}^{\text {outer }} \\
{[\mathrm{MPa}]}\end{array}$ & $\begin{array}{c}\mathbf{K}_{\text {tw }}^{\text {outer }} \\
{[-]}\end{array}$ & $\begin{array}{c}\sigma_{\text {red max }}^{\text {inner }} \\
{[\mathrm{MPa}]}\end{array}$ & $\begin{array}{c}\mathbf{K}_{\text {tw }}^{\text {inner }} \\
{[-]}\end{array}$ \\
\hline $0 / 0$ & 1009,7 & - & 1009,7 & - \\
\hline $4 / 1,2$ & 550,2 & 0,0704 & 1125,5 & 0,7026 \\
\hline $8 / 2,4$ & 499,2 & 0,0111 & 1017,3 & 0,8056 \\
\hline $12 / 3,6$ & - & - & 825,1 & 0,4745 \\
\hline $16 / 4,8$ & - & - & 692,3 & 0,2791 \\
\hline $20 / 6,0$ & - & - & 602,8 & 0,1807 \\
\hline $24 / 7,2$ & - & - & 539,4 & 0,1280 \\
\hline $28 / 8,4$ & - & - & 491,9 & 0,0974 \\
\hline
\end{tabular}

When repairing outer circular failure the situation is the opposite to the previous case. It is seen from Table 7 that an outer circular failure can be repaired better by outer reinforcement than by inner one. Also in this case both failure criteria can already be fulfilled by 8 layers of outer winding. The inner reinforcement with a low number of layers makes the situation worse and the pipe can be fixed only with a very high number of layers. The argumentation for this phenomenon is the same as given at inner failures.

\section{Conclusions}

The numerical experience of the investigations is the following:

- From the engineering point of view the multilayered shell model is a suitable tool for numerical analysis of pipe failures and for investigation of repaired pipes.

- From the mechanical point of view the the insulation layer is negligible.

- The experimental loading case is more hazardous than the normal working conditions.

- The critical strains and stresses are similar at inner and outer circular failures, however the character of deformations is different.

- It is sufficient to use only a few number of CFRP layers for repair of very deep circular failures, if they are applied from the failure side.

- The inner and outer failures have to be fixed by inner and outer reinforcement, respectively.

- The bandwidth in the investigated range of composite layers does not play an important role at the repair of circular failure. 
Acknowledgements. The authors wish to acknowledge the assistance given by the Hungarian Agency for Research Fund Management and Research Exploitation (GVOP-3.1.1.2004-05-0215/3.0) and by the Hungarian Scientific Research Fund (T 049126 and T 048359) for supporting this research.

\section{REFERENCES}

1. Reddy, J. N.: Mechanics of Laminated Composite Plates and Shells, Theory and Analysis, CRC Press, 2004.

2. Matthews, F. L., Davies, G. A. O., Hitchings, D., Soutis, C.: Finite Element Modelling of Composite Materials and Structures, Woodhead Publishing Ltd, Camgridge, 2000.

3. Bathe, K. J.: Finite Element Procedures, Prentice Hall International Editions, 1996.

4. I-DEAS User' Guide, UGS PLM Solutions Inc., 2004.

5. Égert, J., Pere, B., MolnÁr-Égert, É.: Mechanical aspects of fixing pipeline welding failures by reinforcements EMT Technical Rewiev), (2008), 125-131. (in Hungarian)

6. Pere, B., ÉGERT, J.: Finite element modelling opportunities of artificial welding failures and outer damage of pipelines. Proc. microCAD 2008 Int. Sci. Conf. 20-21 March 2008., Section F: Applied Mechanics, 39-44.

7. LukÁCS, J., NAGY, Gy., TÖRÖK, I.: Investigation of some parts of a test pipe. Confernce Proceedings Integrity of hybride pipes reinforced by polymere matrix composites. Miskolc-Egyetemváros, Hungary, (2008), 174-193. (in Hungarian)

8. CzÉL, G.: Special material test methods for polymere composite pipe materials. Confernce Proceedings Integrity of hybride pipes reinforced by polymere matrix composites. Miskolc-Egyetemváros, Hungary, (2008), 17-24. (in Hungarian) 